\title{
US refuses nuclear fuels to South Africa and Pakistan
}

The US state department has withheld approval of licences for the export of highly-enriched uranium to to South Africa and of plutonium to Pakistan, because of concerns about the intentions of each country with regard to the development of nuclear weapons.

The South African request was for 57 pounds of highly-enriched uranium for its Safari research reactor, and was initially filed three years ago. According to the State Department, approval of the licence has been held up "awaiting the outcome of a review of US-South African nuclear cooperative relationships."

In the case of Pakistan, the request was for less than a pound of plutonium which was destined for a research reactor for use in spectrometry research. The State Department has expressed its concern that Pakistan has announced its intention to obtain a reprocessing facility for spent nuclear fuels, which could make it possible for the country to produce enough plutonium for use in nuclear weapons.

Under the terms of the nuclear nonproliferation act, which was signed by the President in March, such factors must now be taken into account in deciding whether or not to grant an export licence for nuclear fuels.

Meanwhile the US is still maintaining its embargo on the export of nuclear fuels to the member countries of Euratom that came into effect last month following Euratom's refusal to renegotiate its existing agreement on nuclear fuel exports.

Sources in Washington said that pending further moves from Brussels, the existing stalemate-which results largely from complaints that the US has acted unilaterally in revoking the existing agreement-could last through to the autumn.

In Brussels the opposition to renegotiation comes principally from France. The other 8 signatories of the Euratom treaty-Britain, Germany, Italy, Belgium, Denmark, Eire, Luxembourg and the Netherlands-are all agreed that a letter could be sent to President Carter expressing willingness to renegotiate the agreement.

France is expected ultimately to capitulate to pressure from the other members to send such a letter. Meanwhile, the problems caused to Europe by the US embargo do not appear to be acute, but they are growing. Half of Europe's medium-enriched uranium comes from the USSR. Nearly all the highly enriched uranium, used in research reactors, comes from the US but "It's not like stopping milk or steel" said a Brussels spokesman last week. "The nuclear supplies are needed only infrequently".

Last year Europe withstood a 9months' stop on the US supply of enriched uranium, while President Carter gathered his thoughts on the issue. But there were special factors operating then. One of the most affected reactors was the high flux neutron beam reactor at the Institute of Laue Langevin at Grenoble. The head of administration at ILL, Dr W Grillo, said last week that the laboratory could not have continued operatinghad it not been for a special allowance of highly enriched uranium supplied by the US because ILL was an international organisation.

Dr Grillo believes that if the present embargo continues, ILL will need to look for a similar concession before long. "The situation is not good," said Dr Grillo. "The American regulations are leading to big delays".

\section{US government to review industrial innovation}

Concerned at the apparent relationship between declining industrial productivity and growing inflation, the White House announced last week that it has initiated a major review of the effect of government policies on technological innovation. The review will cover the activities of all the major government departments and agencies, and is expected to lead to a number of policy options which will be placed before President Carter sometime next year.

The review is largely the outcome of recent studies carried out by Dr Frank Press's Office of Science and Technology Policy, which has been focusing much of its attention on the relationship between economic performance and national investment in research and development. It was on Dr Press's initiative, for example, that the Office of Management and Budget agreed on the need for a significant $11 \%$ increase in support for federally sponsored R \& D which the President requested in his budget proposals for the fiscal year 1979 presented to Congress in January.

A number of issues have given rise to the administration's concern at the current health of industrial innovation in the US.

These include:
- indications that industry tends to 'underinvest' in innovation;

- an increased emphasis in private R \& D in recent years on low-risk, short-term projects directed at incremental product changes rather than at longer-term research leading to new products and processes;

- the declining international competitiveness of some segments of US industry;

- difficulties that small, high-technology firms encounter in obtaining venture capital.

The situation is illustrated by figures recently released by the National Science Foundation which show that since 1970 , industrial $R \& D$ expenditure in constant dollars has increased by less than $1 \%$ while industrial expenditure on basic research has fallen by $1 \%$. The NSF also comments that "barring continued federal increase, basic research in industry is expected to remain constant, in real terms, and could possibly decline".

The innovation study will not be carried out by OSTP, but by an industrial innovation coordinating committee under the chairmanship of the Department of Commerce. It will concentrate on all aspects of federal policy that affect industrial R \& D and innovation, focusing in particular on any "negative impacts" of such policies which might be reduced in a way consistent with other national goals.

This is a direct reference to growing complaints from industry that proliferating government regulations in fields such as environmental and safety controls are one factor that has been inhibiting R \& D efforts, much of which has consequently become "defensive" rather than offensive.

However, speaking at the Massachusetts Institute of Technology last week, Dr Frank Press said that since World War II there had been a dominant pattern by which the federal government supported basic research in universities and federal laboratories leading to the applied $\mathrm{R} \& \mathrm{D}$ which were phased into commercialisation by the private sector. Although this system had worked well, Dr Press said that it was now "essential that we re-evaluate it and see how it might be improved".

Although the precise form of the study has not yet been determined, it is expected that in addition to the studies that will be carried out by individual departments and agencies, arrangements will be made at a relatively early stage for public discussion of the issues involved.

David Dickson 